Military Technical College Kobry El-Kobbah, Cairo, Egypt

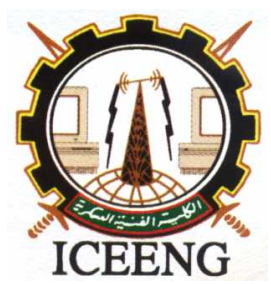

\author{
$6^{\text {th }}$ International Conference \\ on Electrical Engineering \\ ICEENG 2008
}

\title{
Java software platform for energy and environmental buildings management
}

\author{
By \\ Kafetzis G.* \\ Patelis P.* \\ Stavrakakis G.S.* \\ Kolokotsa D.**
}

\section{$\underline{\text { Abstract: }}$}

The adjustment of energy and environmental parameters is essential for the good human adaptability, in a building. The best possible internal conditions ensure the health, comfort and improve the productivity of the residents. Another important goal is the reduction and minimization of the energy consumption. National and international standards have been developed in order to achieve good indoor environmental quality conditions. This paper presents the development of a Java software platform which performs environmental and energy classification for buildings based on national standards. CEN (Centre Europeen de Normalisation) standard and LEED Green Building Rating System have been selected for the classification of the building's environmental behaviour. The design procedure is illustrated and the classification results, using data recorded by a building energy management system, installed in the laboratory, are presented.

\section{Keywords:}

Environmental classification, standards, java platform, human adaptability

* Department of Electronic \& Computer Engineering Technical University of Crete

** Department of Natural Resources and Environment Laboratory of Renewable Energy Engineering Technological Educational Institute of Crete 


\section{Introduction:}

The research in Energy and Environmental Building Management has been evolved over the years. Scientists turn their attention to the adjustment of energy and environmental parameters prevailing in a building. Parameters such as temperature, relative humidity, lighting and carbon dioxide concentration are responsible for the human adaptability in a building. There are two major challenges that must be encountered: a) to provide to the residents the best possible conditions of the air quality, the optical, thermal and acoustic comfort and b) the reduction and minimization of the energy consumption without affecting the indoor conditions and causing discomfort to the residents. The achievement of the best possible internal conditions ensures the health, comfort and improves the productivity of the residents. [1,5]

The analysis of the indoor environmental quality conditions (air quality, optical, thermal, acoustic comfort and energy consumption) is (quite) complicated.

Several approaches have been proposed in order to achieve human adaptability and reduction of building's energy consumption. This paper describes the development of software platform, which evaluates and performs environmental and energy classification for buildings based on national standards (e.g. CEN). This software was developed in Java programming language using Netbeans IDE under Linux operation system. Java language was chosen because: a) it provides a stand alone application which may be executed under several operation systems (Windows, UNIX, Macintosh and Solaris), b) it helps on developing an open source application. The idea of an open source application allows the improvement and expansion of the application by other members of the scientific community.

Section 2 presents a brief description of the Java application. Section 3 deals with the environmental classification methodology, based on LEED rating system. On section 4, the environmental classification method, based on CEN standards, is presented. Section 5 presents the experimental results of the environmental classification method using data of a BEM system installed in the laboratory of Electric Circuits and Renewable Energy Sources at the Technical University of Crete. Finally, on the sixth section there is a short description of the energy classification methods that are under development.

\section{Java Application Description:}

The application is divided into two major sections. The first is responsible for the gathering of building's information that describes the environmental and the energy behavior of the building. The second implements the classification mechanism and processes the data of the building. Building's information is stored in an embedded database (implemented in Java DB). Each building is divided into zones and each 
zone's environmental performance is described by several parameters (Temperature, $\mathrm{CO}_{2}$ concentration, Relative Humidity, Lighting and Mean Radiant Temperature). A text file is stored for each parameter which contains hourly measurements, taken by a Building Energy Management System. Moreover, data which describe energy performance are stored. Energy data are divided into the following categories: Heating Period (Electricity, Oil, Gas consumption), Cooling Period (Electricity), Lighting and Appliances.

\section{Enviromental Classification - Leed Green Building Rating system:}

The application implements a methodology, for the environmental classification of buildings, which is based on the LEED (Leadership in Energy and Environmental Design) Green Building Rating System. The (LEED) Green Building Rating System was created by the U.S. Green Building Council (USGBC) to establish a "common standard of measurement" for "green" buildings. LEED is the official methodology for the environmental classification of buildings in U.S. [3]

The application implements an adaptation of LEED methodology in Greek and European standards. LEED certification is based on a point system. There are 71 possible points and five certification levels (A-E). The available points are organized into five broad categories: a) Sustainable Sites, b) Water Efficiency, c) Energy and Atmosphere, d) Materials and Resources and e) Indoor Environmental Quality. These categories contain requirements that describe the environmental behaviour of the building. An amount of points are assigned to these requirements. Table 1 presents the categories and the possible points for each category.

Table (1): Categories and possible points

\begin{tabular}{|c|c|}
\hline LEED Categories & Possible Points \\
\hline Sustainable Sites & 15 \\
\hline Water Efficiency & 5 \\
\hline Energy and Atmosphere & 22 \\
\hline Materials and Resources & 14 \\
\hline Indoor Environmental Quality & 15 \\
\hline Sum of points for all categories & $\mathbf{7 1}$ \\
\hline
\end{tabular}

Table 2 presents the five certification levels and the amounts of points that determine them. 
Table (2): Certification Levels

\begin{tabular}{|c|c|}
\hline Certification Levels & Points \\
\hline A & $54-71$ \\
\hline B & $41-53$ \\
\hline C & $31-40$ \\
\hline D & $19-30$ \\
\hline E & $0-18$ \\
\hline
\end{tabular}

Application implements this adaptation of LEED methodology as a questionnaire. The questionnaire is divided into five sections (tabs) one for each LEED category. Each section contains these requirements (in a Yes/No form) that must be fulfilled in order to earn all possible category points. The classification of the building results from the addition of points (credits) of positive fulfilled requirements. The user can view a filled questionnaire and its results at any time by choosing it from the list of questionnaires for a certain building. Figure 1, shows an example of a LEED questionnaire classification.

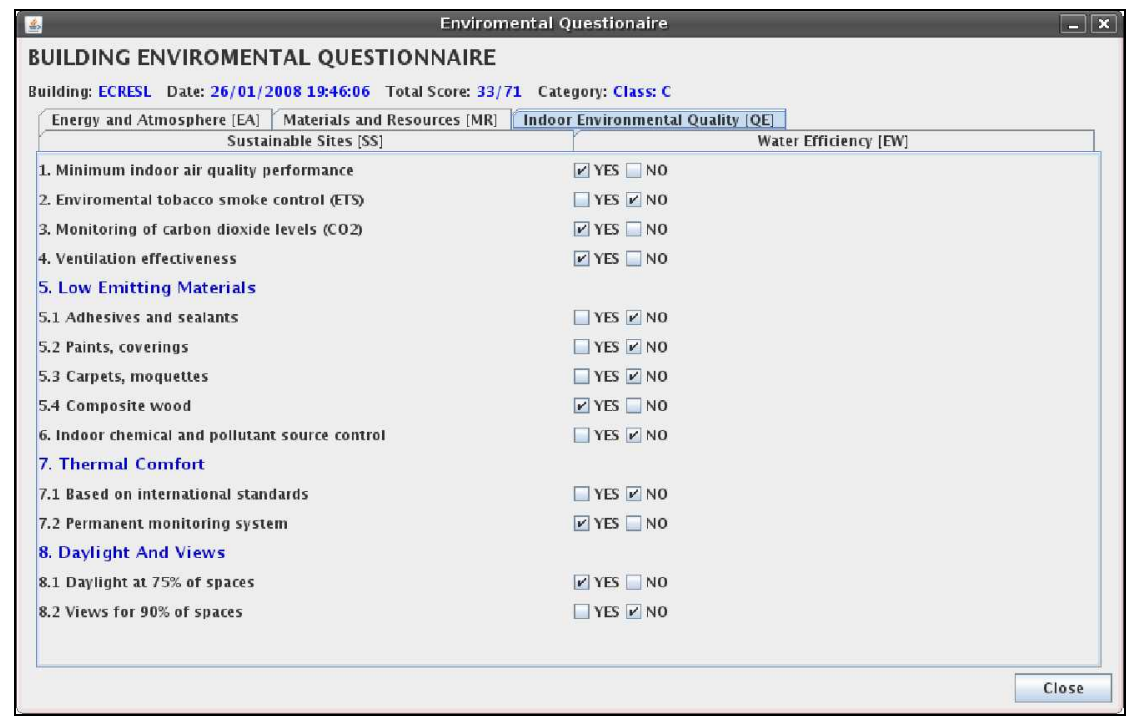

Figure (1): Leed's Questionnaire

\section{Enviromental Classification-CEN(Centre Europeen de Normalisation) standard:}

A more detailed method for the environmental classification of buildings is implemented. This method follows the CEN (Centre Europeen de Normalisation) standard, prEN 15251:2006 (Criteria for the indoor environment including thermal, indoor air quality, light and noise). This standard sets the criteria for the improvement 
and classification of the indoor environmental parameters. Thermal comfort is classified according to an adaptive thermal model which contains adaptive temperature limits. Humidity, Lighting and $\mathrm{CO}_{2}$ concentration are classified according to maximum and minimum limits for different type of buildings and different heating/cooling periods.

\subsection{Thermal Comfort Classification}

Unlike other models, such as Fanger's PMV-model [6,8], thermal comfort model takes the effects of behavioural and psychological adaptation into account. Behavioural adaptation can be discerned in personal, technical, environmental, cultural and organizational adaptation. Psychological adaptation implies a changed perception of, or response to, sensory information.

Thermal comfort classification is based on a new approach of the adaptive thermal model of CEN standard (prEN 15251:2006), as referred to [5]. This new model introduces two building or climate types: Alpha and Beta. A Beta building is an airconditioned building while an Alpha building is not (free-running). In Figures 2, 3, limits are specified for 90, 80 and 65\% acceptance of the thermal indoor climate.
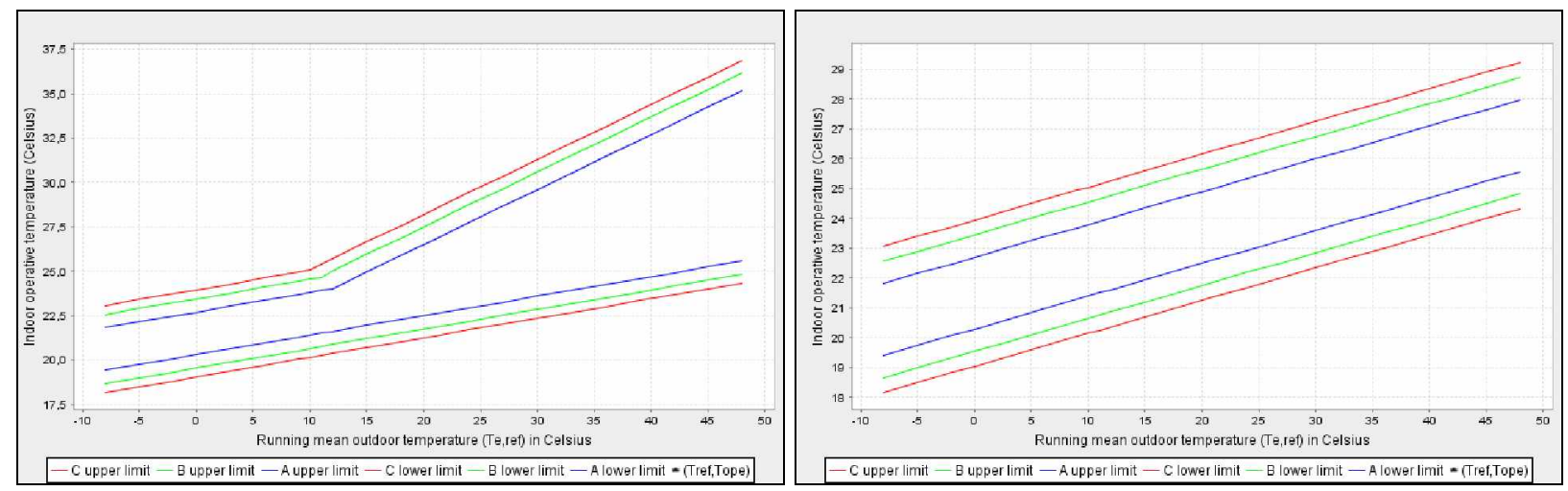

Figure (2,3 ): Building/Climate type Alpha and Beta

Vertical axis indicates the indoor operative temperature which is calculated as the arithmetic mean of the air temperature and the Mean Radiant Temperature (MRT).

$T_{\text {oper }}=\frac{T_{\text {indoor }}+T_{r}}{2}$

Horizontal axis indicates an adapted version of the running mean outdoor temperature $\left(T_{e, r e f}\right) . T_{e, r e f}$ is calculated from the averages of the maximum and minimum outdoor air temperature of the day under study and the three preceding days. 
$T_{e, r e f}=\frac{T_{o, n}+0,8 T_{o, n-1}+0,4 T_{o, n-2}+0,2 T_{o, n-3}}{2,4}$

A building belongs to a class when the limits of the class are not exceeded at any point in time. Each pair of $\left(T_{e, r e f}, T_{\text {oper }}\right)$ must be inside the limit lines of the class. Table 3 shows the formulas belonging to the limit lines. A 'good' indoor climate is characterized by $80 \%$ acceptance (Class B). Around Class B two classes have been defined. Class A is used for extra high quality buildings (very good) and Class $\mathrm{C}$ for buildings with an indoor climate that is acceptable as such. When the limit values of Class $\mathrm{C}$ are exceeded at any point in time, the indoor climate is inadequate (None).

Table (3): Thermal Comfort Classes

\begin{tabular}{|c|c|c|c|c|c|}
\hline \multirow{3}{*}{ Class } & \multirow{3}{*}{ Acceptance } & \multicolumn{4}{|c|}{ Building/Climate type } \\
\hline & & \multicolumn{2}{|c|}{ Alpha } & \multicolumn{2}{|c|}{ Beta } \\
\hline & & Upper Limit & Lower Limit & Upper Limit & Lower Limit \\
\hline A & $90 \%$ & $\begin{array}{l}T_{e, r e f}>12^{\circ} \mathrm{C}: \\
T_{\text {oper }}<20,3+0,31 T_{e, r e f} \\
T_{e, \text { ref }}<12^{\circ} \mathrm{C}: \\
T_{\text {oper }}<22,7+0,11 T_{e, r e f}\end{array}$ & $T_{\text {oper }}>20,3+0,11 T_{e, r e f}$ & $T_{\text {oper }}<22,7+0,11 T_{e, r e f}$ & $T_{\text {oper }}>20,3+0,11 T_{e, r e f}$ \\
\hline B & $80 \%$ & $\begin{aligned} T_{e, r e f}>11^{\circ} \mathrm{C}: \\
T_{\text {oper }}<21,3+0,31 T_{e, r e f} \\
T_{e, r e f}<11^{\circ} \mathrm{C}: \\
T_{\text {oper }}<23,45+0,11 T_{e, r e f}\end{aligned}$ & $T_{\text {oper }}>19,55+0,11 T_{e, r e f}$ & $T_{o p e r}<23,45+0,11 T_{e, r e f}$ & $T_{\text {oper }}>19,55+0,11 T_{e, \text { ref }}$ \\
\hline $\mathrm{C}$ & $65 \%$ & $\begin{array}{l}T_{e, r e f}>10^{\circ} \mathrm{C}: \\
T_{\text {oper }}<22+0,31 T_{e, r e f} \\
T_{e, r e f}<10^{\circ} \mathrm{C}: \\
T_{\text {oper }}<23,95+0,11 T_{e, r e f}\end{array}$ & $T_{\text {oper }}>19,05+0,11 T_{e, \text { ref }}$ & $T_{\text {oper }}<23,95+0,11 T_{e, \text { ref }}$ & $T_{\text {oper }}>19,05+0,11 T_{e, \text { ref }}$ \\
\hline
\end{tabular}

\subsection{Relative Humidity Classification}

Humidity has only a small effect on thermal sensation and perceives air quality in the rooms of sedentary occupancy. However, long term high humidity indoors will cause microbial growth, and very low humidity causes dryness and irritation of eyes and airways.

Application implements the humidity classification based on the CEN standard, prEN 15251:2006 [1]. Standard recommends design values of indoor humidity for occupied spaces for dimensioning of dehumidification and humidification systems. Table 4 shows the categories of humidity classification and the limits of each category. 
Table (4): Relative Humidity Classification Categories

\begin{tabular}{|c|c|c|}
\hline \multirow{2}{*}{ Category } & \multicolumn{2}{|c|}{ Relative Humidity Limits, \% } \\
\cline { 2 - 3 } & Upper (dehumidification) & Lower (humidification) \\
\hline I & 50 & 30 \\
\hline II & 60 & 25 \\
\hline III & 70 & 20 \\
\hline IV & $>70$ & $<20$ \\
\hline \hline
\end{tabular}

The average relative humidity is calculated for each day of study, as the sum of hourly relative humidity values (during occupancy time) divided by the occupancy hours.

$r h_{d a y, a v g}=\frac{\sum_{1}^{n} r h_{h o u r l y}}{\sum_{1}^{n} h o u r s}$, where $\mathrm{n}$ is the number of occupancy hours

A building belongs to the category with the greater percentage of days inside its limits. In case two categories have equal percentages of days, then the worse category is the one that dominates. This is because the goal of the classification is to improve building indoor conditions.

\section{$\underline{4.3 \text { Lighting Classification }}$}

In most cases, the use of daylight instead of artificial is preferred due to health, comfort and energy. This depends on many factors like standard occupancy hours, the portion of occupancy time during which there is enough daylight, location of the building (latitude), amount of daylight hours during summer and winter, etc.

Application implements the lighting classification based on the CEN standard, prEN 12464-1:2002[4]. Standard recommends design illumination levels for some buildings and spaces. Table 5 shows the categories of lighting classification and the limits of each category for the types of buildings supported by the application.

Table (5): Lighting Classification Categories

\begin{tabular}{||c|c|c|c||}
\hline \multirow{2}{*}{ Category } & \multicolumn{3}{|c|}{ Building Type } \\
\cline { 2 - 4 } & Office & School & Shop \\
\hline Adequate & $\geq 5001 \mathrm{x}$ & $\geq 3001 \mathrm{x}$ & $\geq 3001 \mathrm{x}$ \\
\hline Inadequate & $<5001 \mathrm{x}$ & $<3001 \mathrm{x}$ & $<3001 \mathrm{x}$ \\
\hline
\end{tabular}

The arithmetic mean of luminance is calculated for each day of study, by the maximum 
and minimum indoor luminance during occupancy time.

$E_{d a y, a v g}=\frac{E_{d a y, \min }+E_{d a y, \max }}{2}$

The choice of the minimum and maximum luminance values for the daily average luminance is explained as follows: The supported building types of the application usually have an occupancy time during the day where there is adequate lighting (e.g. during office hours). In case that average luminance value results from all luminance measurements, an inadequate luminance measurement will affect the calculation of the average in a small portion. The classification result will be affected by this measurement in a small portion too.

A building belongs to the category with the greater percentage of days inside its limits. In case two categories have equal percentages of days, then inadequate category is the one that dominates.

\subsection{Carbon Dioxide Classification}

Carbon dioxide concentration affects, in a large portion, the indoor environmental quality. In indoor spaces occupied by people the carbon dioxide concentration will reach higher levels than in pure outdoor air. High concentrations levels will cause discomfort in more than $20 \%$ of occupants, and the discomfort will increase with increasing $\mathrm{CO}_{2}$ concentration. At 2,000 ppm the majority of occupants will feel a significant degree of discomfort, and many will develop nausea and headaches.

Application implements the carbon dioxide classification according to the categories, presented in Table 6.

Table (6): Carbon Dioxide Classification Categories

\begin{tabular}{||c|c|}
\hline Category & CO $_{2}$ Limits, ppm \\
\hline Accepted & $\leq 700$ \\
\hline Marginal & $>700$ and $\leq 800$ \\
\hline Unaccepted & $>800$ \\
\hline
\end{tabular}

The average carbon dioxide concentration is calculated for each day of study, as the sum of hourly concentration values (during occupancy time) divided by the occupancy hours. 
$C O_{2 \text { day,avg }}=\frac{\sum_{1}^{n} \mathrm{CO}_{2 \text { hourly }}}{\sum_{1}^{n} \text { hours }}$, where $\mathrm{n}$ is the number of occupancy hours

A building belongs to the category with the greater percentage of days inside its limits. In case two categories have equal percentages of days, then the worse category is the one that dominates.

An additional concentration level has been introduced at $300 \mathrm{ppm}$ (outdoor fresh air concentration). This level does not represent a category, but it is essential for the validation of measurements. If a daily average $\mathrm{CO}_{2}$ concentration is lower than $300 \mathrm{ppm}$ then this measurement is invalid and is excluded from the classification mechanism. This may mean a problem in the $\mathrm{CO}_{2}$ sensor.

\section{Experimental Results of Building Management Application}

The application was tested and evaluated using data, recorded by a building energy management system, installed in the laboratory of Electric Circuits and Renewable Energy Sources at the Technical University of Crete, Greece. Data constitutes of hourly measurements of the following environmental parameters: Outdoor and Indoor Temperature, Mean Radiant Temperature (MRT), Relative Humidity, Carbon dioxide concentration and Lighting (Indoor luminance). They are organized into files and are inserted in the application. The measurements lasted eighty one days, starting from 01/12/2006 01:00 and ended at 19/02/2007 23:00. The daily occupancy hours of the laboratory were from 08:00 to 18:00.

The environmental classification results and the charts, produced by the application, of each measured parameter are presented below.

\subsection{Thermal Comfort Classification Results}

The classification's result indicates that the indoor climate of the laboratory is inadequate. Although, many points are inside classes' limits, the building does not belong to a class because several points exceed the limit values of Class C. Figures 4, 5 present the classification's charts of thermal comfort. 

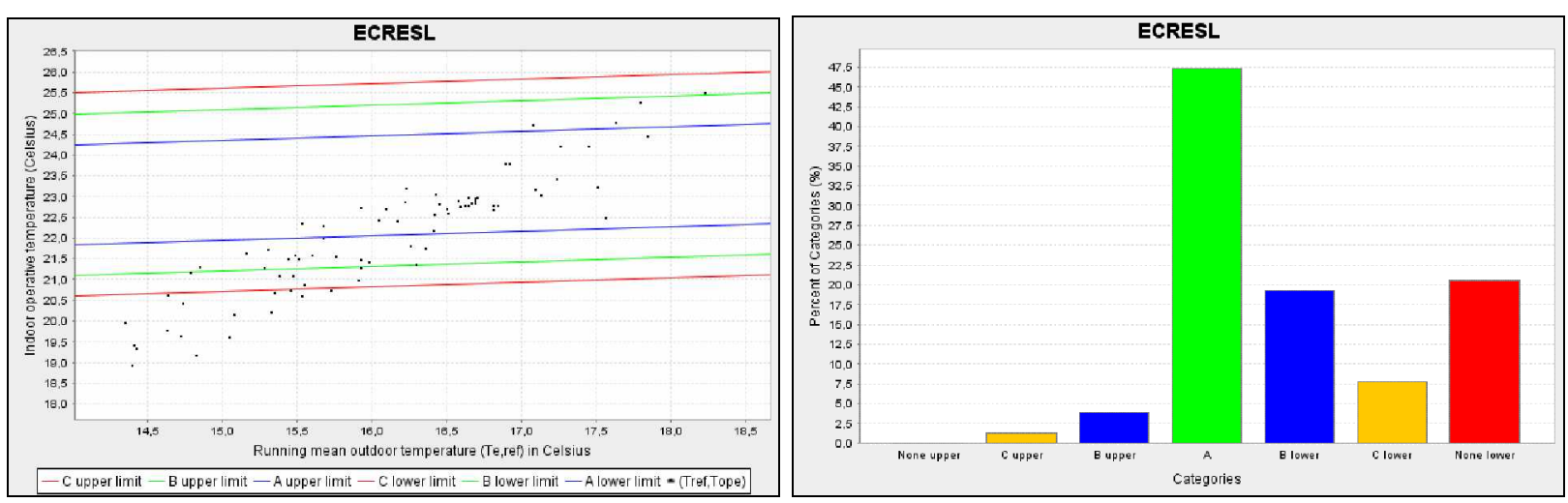

Figures (4,5): Classification Results of Thermal Comfort

\subsection{Relative Humidity Classification Results}

The classification's result indicates that the building belongs to category I. The greater percentage of days belongs to category I. Relative humidity remains in acceptable limits and there is no need for dehumidification or humidification during occupancy hours. Figures 6, 7 present the classification's charts of relative humidity.
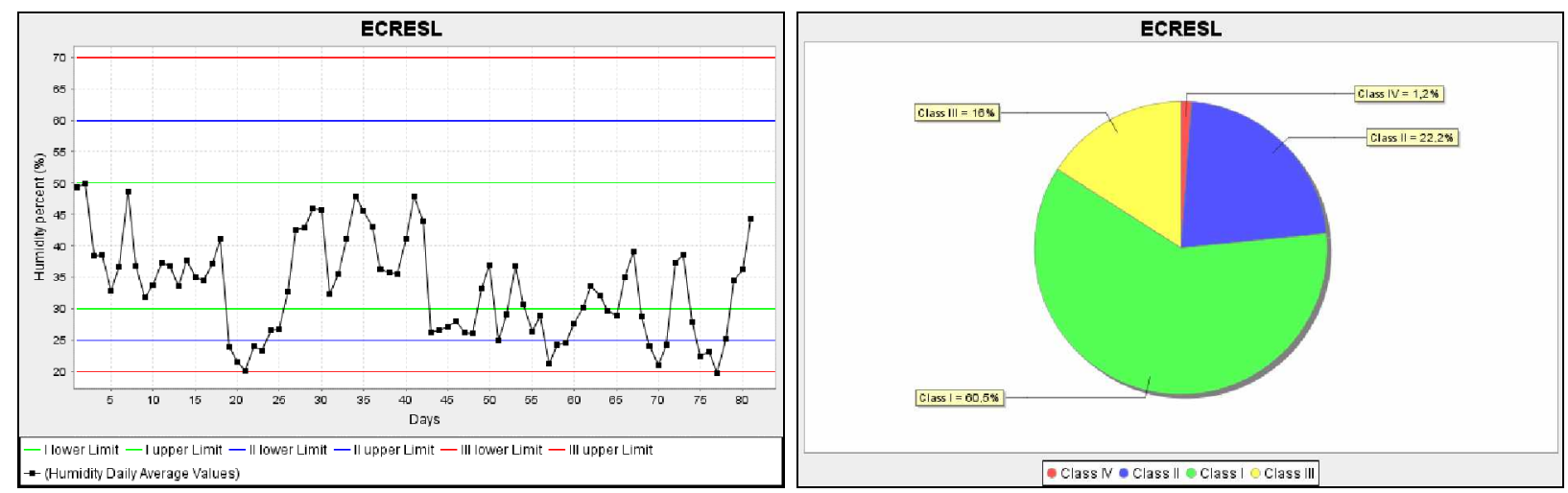

Figure (6,7): Classification Results of Relative Humidity

\subsection{Lighting Classification Results}

The classification's result indicates that the building has adequate lighting during occupancy hours. The luminance levels are secured by the proper combination of daylight and artificial light. Figures 8, 9 present the classification's charts of lighting. 

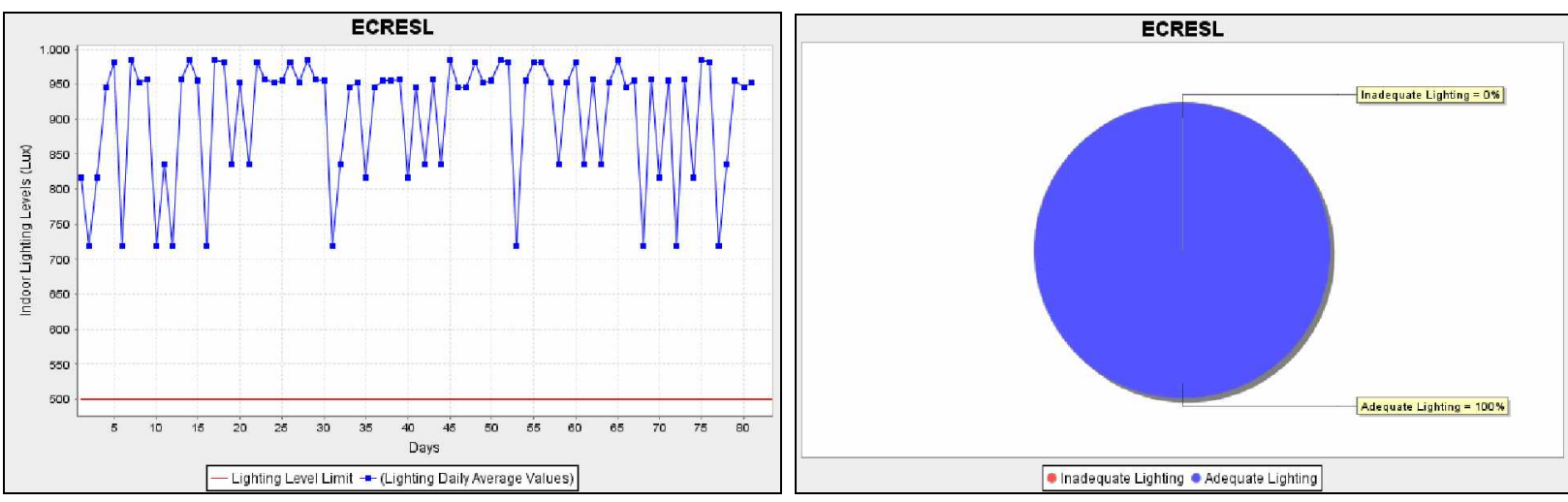

Figure (8,9): Classification Results of Lighting

\subsection{Carbon Dioxide Classification Results}

The classification's result indicates that the levels of carbon dioxide concentration are acceptable, during occupancy hours. The indoor air quality of the laboratory does not cause discomfort to the residents. Figures 10, 11 present the classification's charts of $\mathrm{CO}_{2}$.
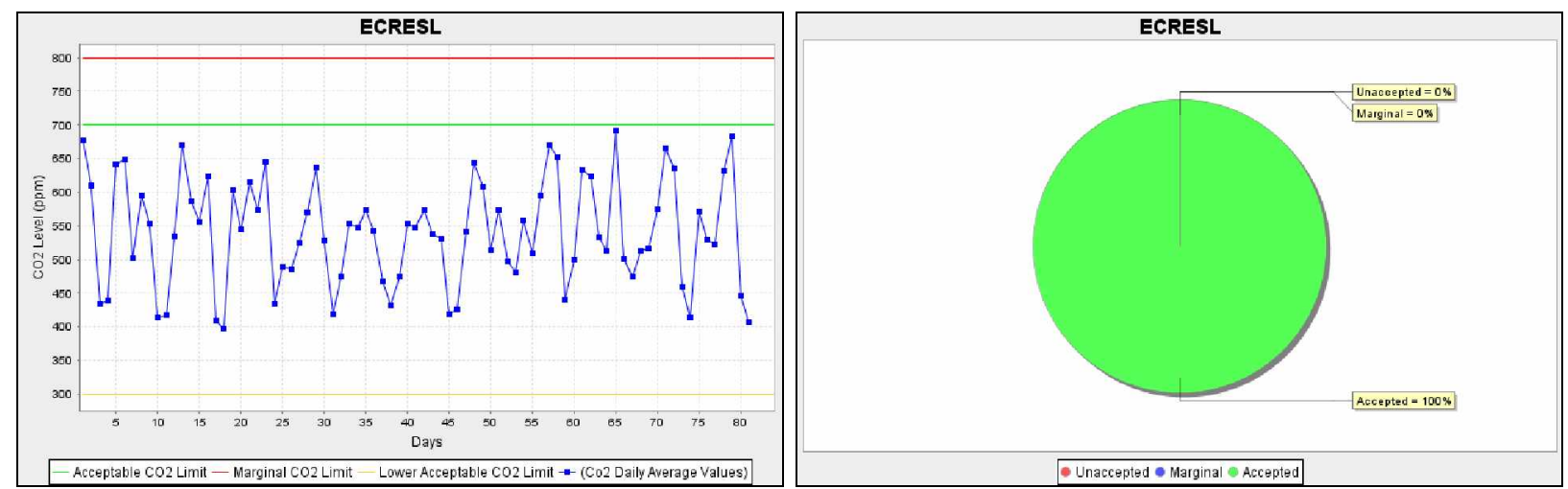

Figure (10,11): Classification Results of Carbon Dioxide

The overall environmental classification results for the laboratory of Electric Circuits and Renewable Energy Sources, are presented in Table 7. 
Table (7): Overall Environmental Classification Results

\begin{tabular}{|c|c|c|c|c|}
\hline \multicolumn{5}{|c|}{ ECRES Laboratory Environmental Classification } \\
\hline Parameter & $\begin{array}{c}\text { Thermal } \\
\text { Comfort }\end{array}$ & $\begin{array}{c}\text { Relative } \\
\text { Humidity }\end{array}$ & $\begin{array}{c}\text { Carbon } \\
\text { Dioxide }\end{array}$ & Lighting \\
\hline $\begin{array}{c}\text { Classification } \\
\text { Category }\end{array}$ & None & I & Accepted & Adequate \\
\hline
\end{tabular}

\section{Energy Classification}

The energy classification part of the application is under development. Energy classification is based on two major methods: a) simplified and b) detailed method. Simplified method offers the choice of two methodologies: Degree - Days and Climate Severity Index (CSI). The first one is based on the degree - days parameter, according to the building's location and the second one is based on the climatologic conditions of the location. Detailed method is more analytical and is based on the information (data) that describe the energy behaviour of a building. There are four categories of data: Cooling, Heating, Lighting and Appliances that include the main energy consuming parameters in a building.

\section{Conclusion}

This paper presented the development of a java platform for the environmental and energy classification of buildings, based on international standards. The environmental classification results derived using LEED Green Building Rating System and CEN standards. The platform was tested and evaluated, using recorded data taken from the laboratory energy management system installation. The application results were proven to be valid and consistent to the standards' specifications. The environmental classification indicated that thermal comfort's parameters must be improved in order to achieve the best possible internal conditions for the residents working in the laboratory. On the contrary, the parameters affecting the optical comfort and the indoor air quality are satisfactory. 


\section{References:}

[1] CEN prEN15251, 2006 Criteria for the Indoor Environment including thermal, indoor air quality, light and noise.

[2] ASHRAE Standard 55-2004, Thermal Environmental Conditions for Human Occupancy, ISSN 1041-22336.

[3] U.S. Green Building Council, Green Building Rating System For New Construction \& Major Renovations (LEED-NC) Version 2.1, November 2002

[4] CEN EN 12464-1:2002, Light and lighting. Lighting of work places. Indoor work places

[5] A.C. van der Linden , A.C. Boerstra, A.K. Raue, S.R. Kurvers, R.J. de Dear, Adaptive temperature limits: A new guideline in The Netherlands A new approach for the assessment of building performance with respect to thermal indoor climate, Elsevier B.V. Energy and Buildings 38 (2006) 8-17

[6] P.O. Fanger, Thermal Comfort Analyses and Applications in Environmental Engineering, McGraw-Hill, London, New York, ISBN 0-07-019915-9, 1970.

[7] P.O. Fanger, J. Toftum, Extension of the PMV model to non airconditioned buildings in warm climates, Energy and Buildings 34 (2002) 533-536.

[8] P.O.Fanger, Thermal comfort, Mc Graw-Hill, New York, ISBN-10: 0070199159 1972.

[9] WHO, Air Quality Guidelines for Europe, World Health Organization; 2Rev Ed edition (January 1, 2000) ISBN-10: 9289013583 